$\angle$ Buliolob

\title{
Kinetics of cathodic reduction of oxygen on Ni-Cr-Mo-W alloy.
}

Presented to:

210th Meeting of The Electrochemical Society

Presented by:

D. Zagidulin.

Ph. D., The University of Western Ontario

November 1, 2006

Cancun, Mexico 


\section{Acknowledgements.}

- We are grateful to Surface Science Western for surface analyses

- Support of the Science and Technology Program of the Office of the Chief Scientist (OCS), Office of Civilian Radioactive Waste Management (OCRWM), U.S. Department of Energy (DOE) is gratefully acknowledged. The work was performed under the Corrosion and Materials Performance Cooperative, DOE Cooperative Agreement Number: DE-FC28-04RW12252

- The views, opinions, findings, and conclusions or recommendations of authors expressed herein do not necessarily state or reflect those of the DOE/OCRWM/OCS 

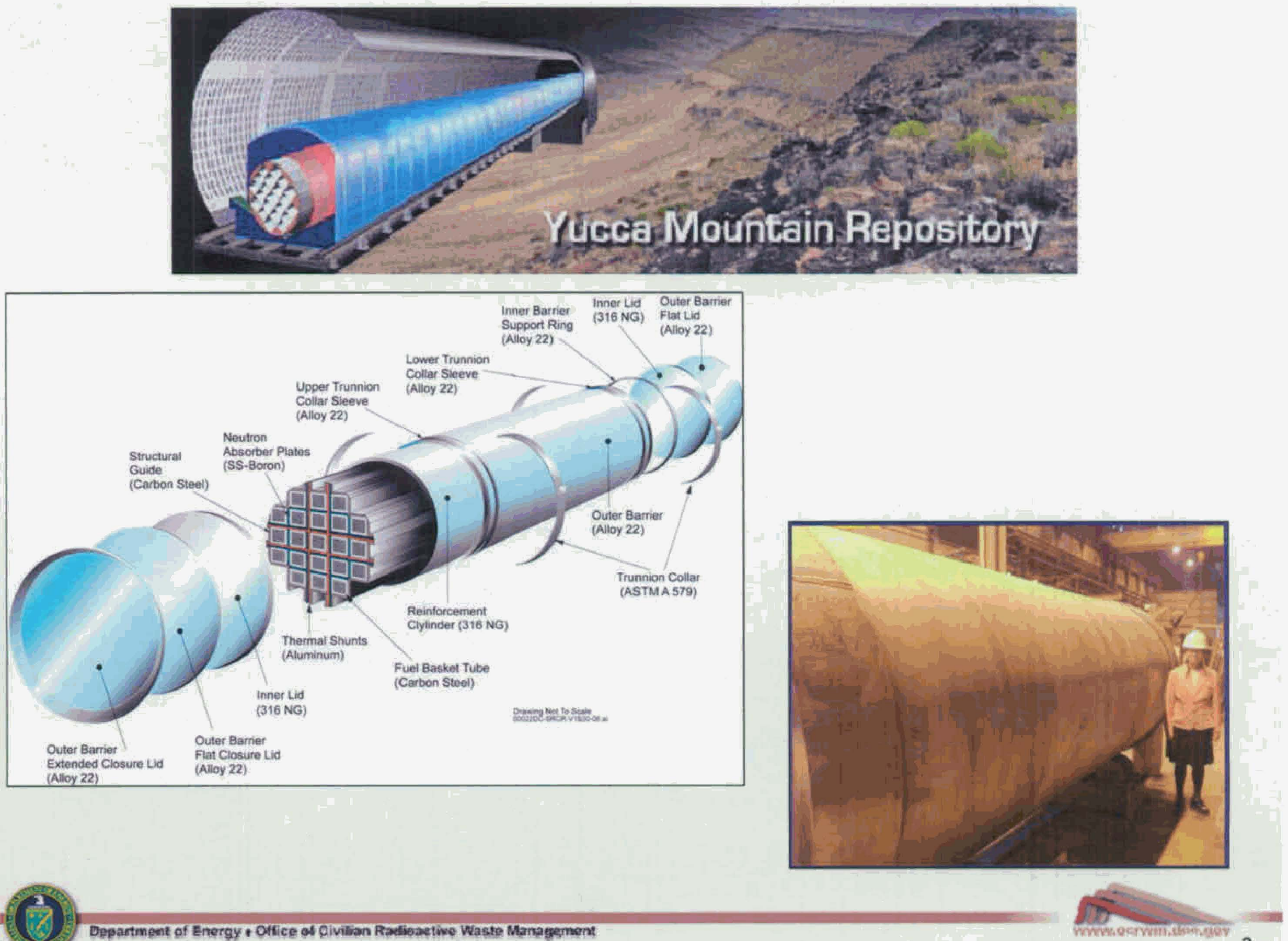


\section{Kinetics of cathodic reduction...}

\section{Composition of Alloy 22.}

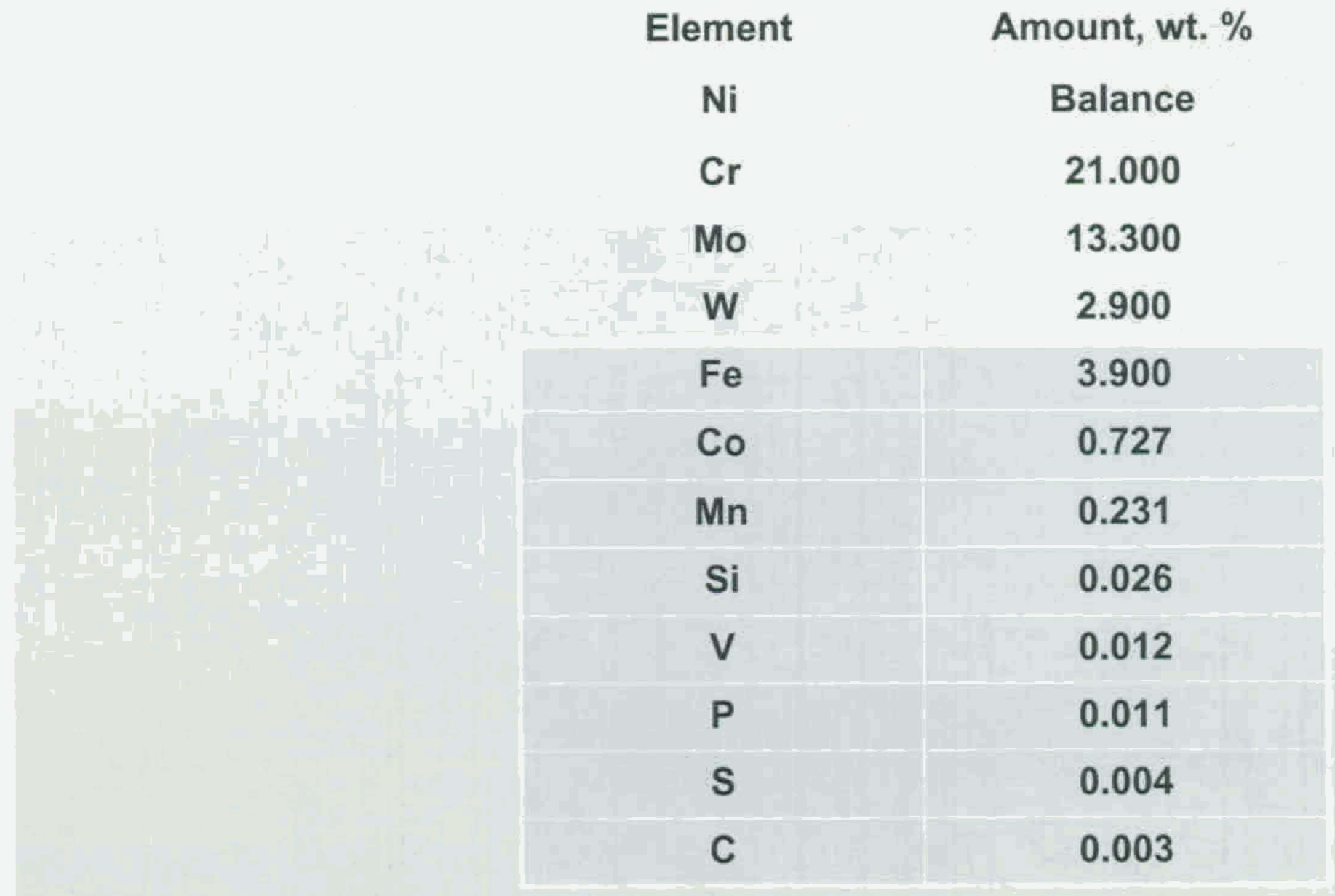




\section{Kinetics of cathodic reduction...}

Main directions of the research.

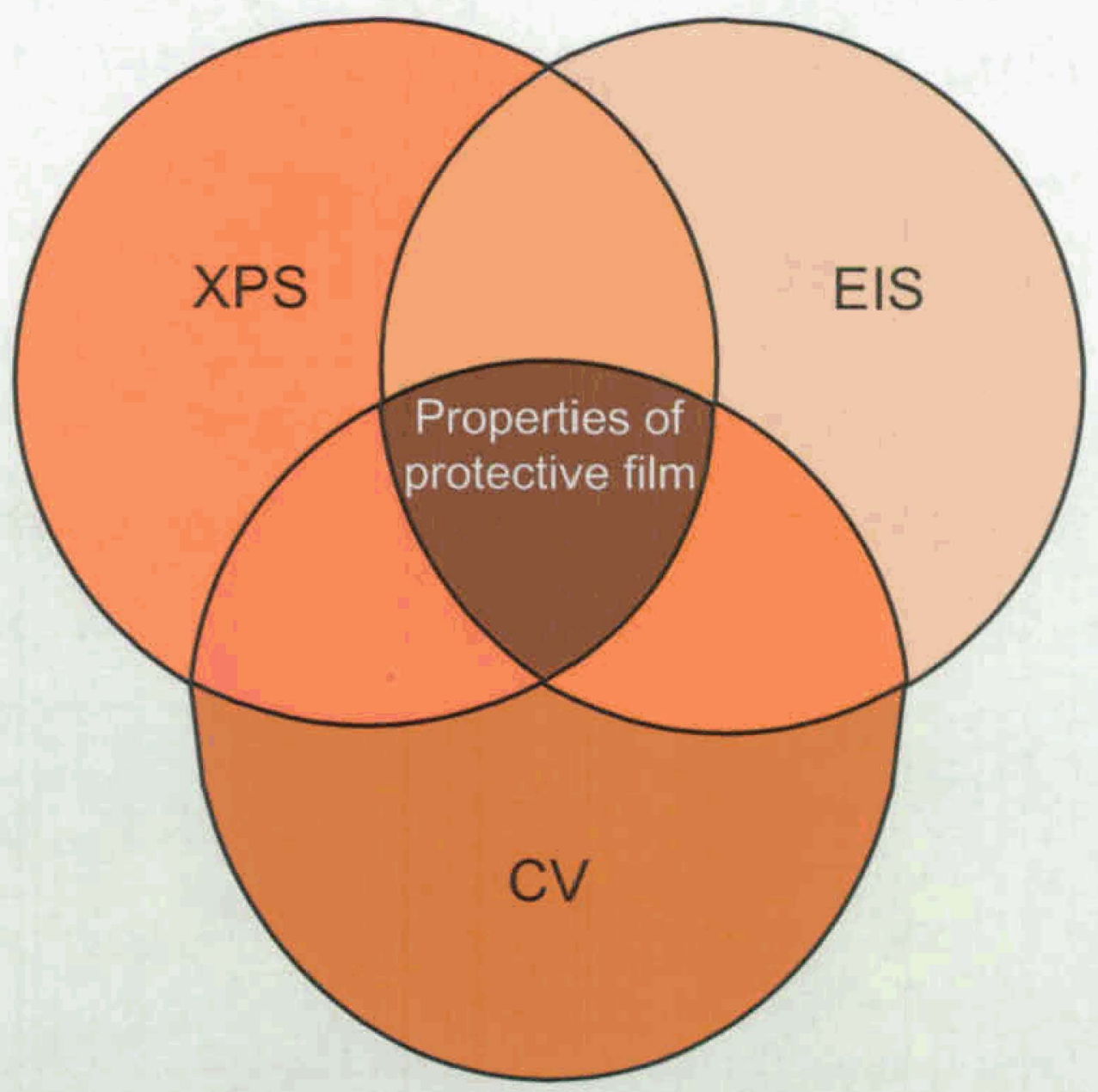




\section{Kinetics of cathodic reduction... \\ Experimental conditions.}

- Solution:

- $5 \mathrm{~mol} \mathrm{~L}^{-1} \mathrm{NaCl}$

- Temperature: $30^{\circ} \mathrm{C}-90^{\circ} \mathrm{C}$

- Saturated with $\mathrm{O}_{2}$ or deaerated by $\mathrm{Ar}$

- Conventional three-electrode electrochemical cell

- Working electrode - Alloy 22 sample with geometric surface areas $0.785 \mathrm{~cm}^{-2}$

- $\mathrm{Ag} / \mathrm{AgCl}$ reference electrode; $\mathrm{E}=0.199 \mathrm{~V}$ vs. NHE

- Pt counter electrode

- RDE used to minimize the influence of diffusion processes while measuring cyclic voltammograms. The angular velocity of the electrode was $23.5 \mathrm{~Hz}$ 


\section{Kinetics of cathodic reduction... XPS experimental conditions.}

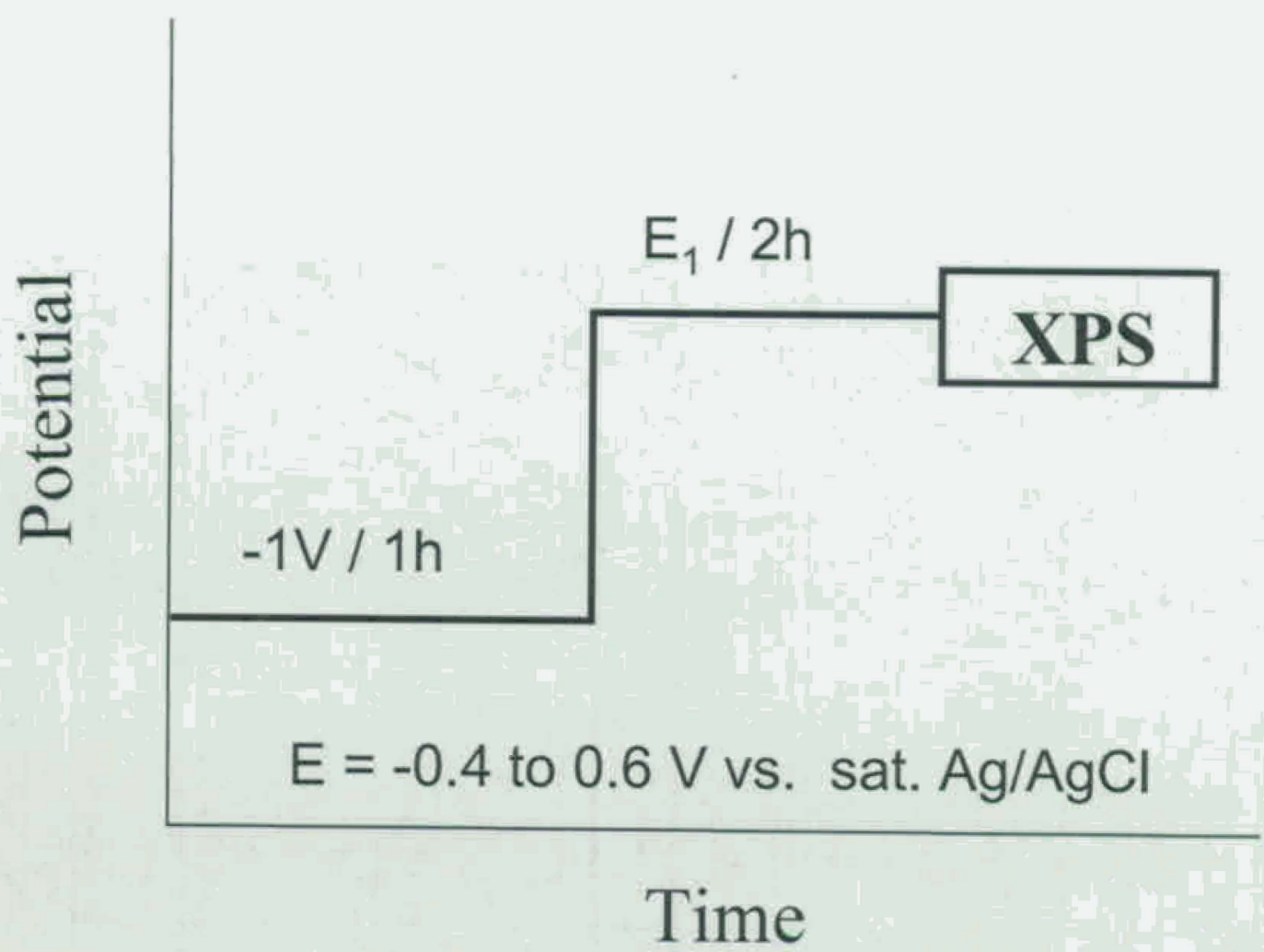

$\mathrm{O}_{2}$ free solution $/ 30^{\circ} \mathrm{C}$ 


\section{Kinetics of cathodic reduction...}

\section{Surface Analysis. XPS Survey Spectra.}

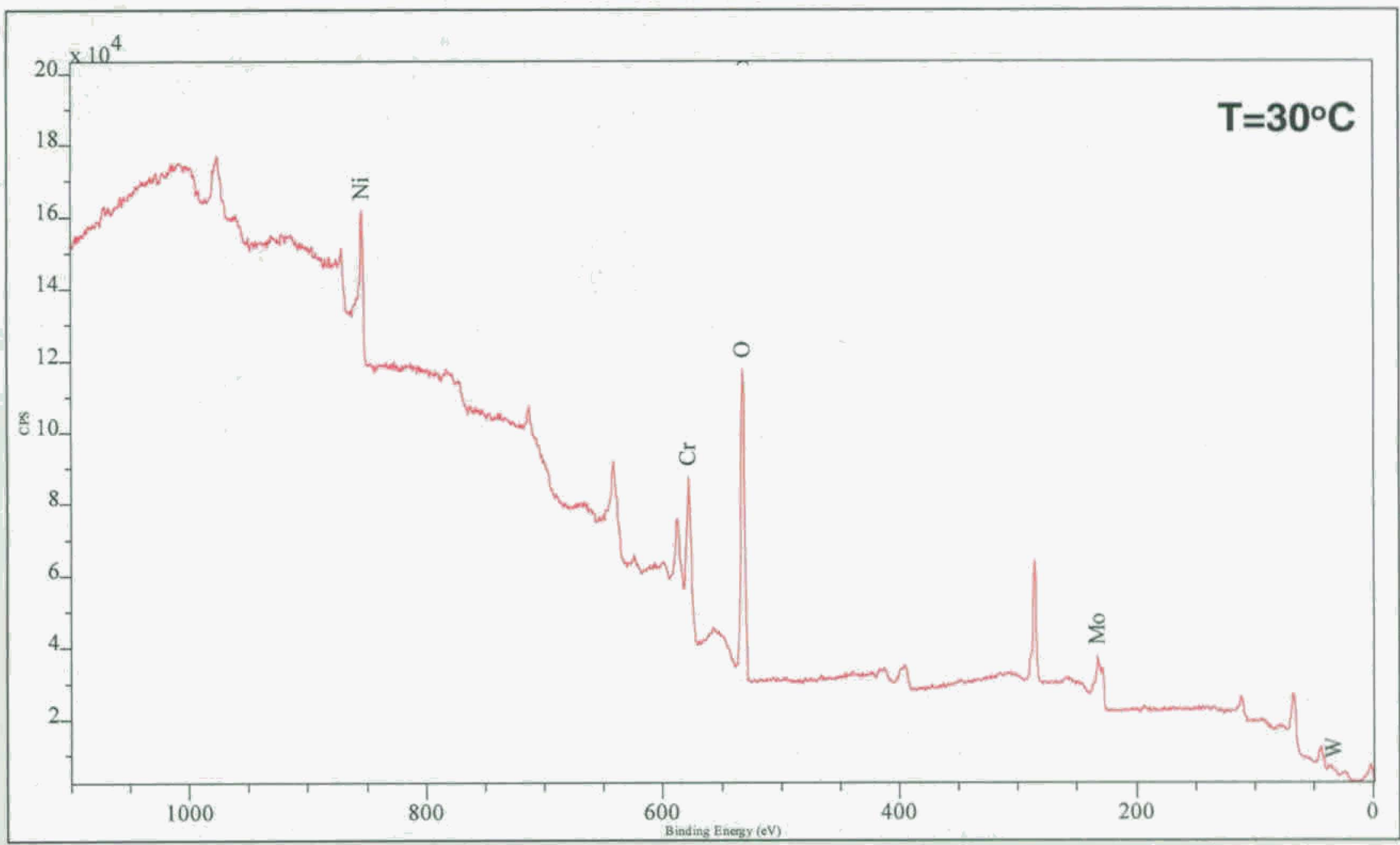




\section{Kinetics of cathodic reduction...}

Surface Analysis. Ni High Resolution XPS.

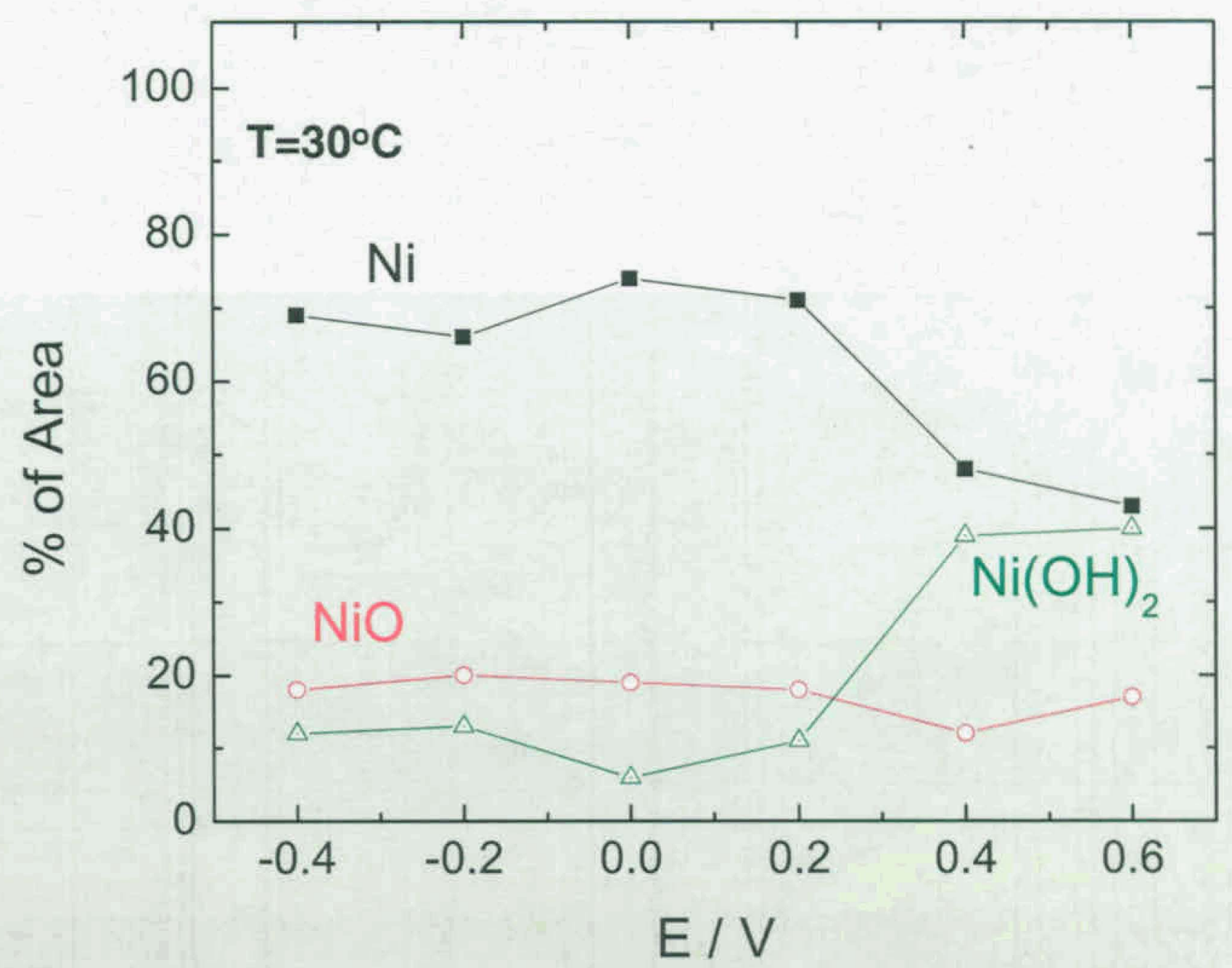


Kinetics of cathodic reduction...

Surface Analysis. Cr High Resolution XPS.

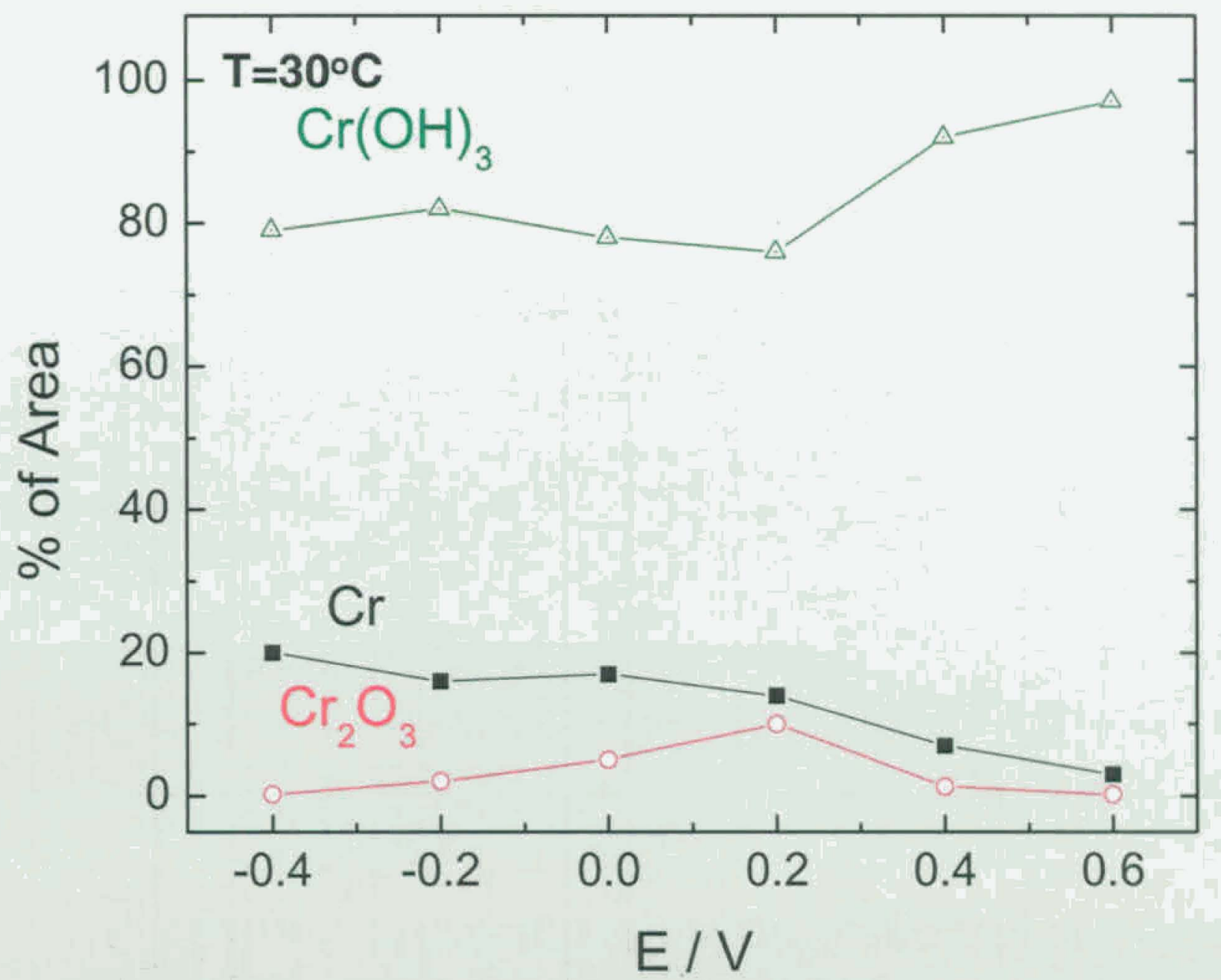




\section{Kinetics of cathodic reduction...}

\section{Surface Analysis. Mo High Resolution XPS.}

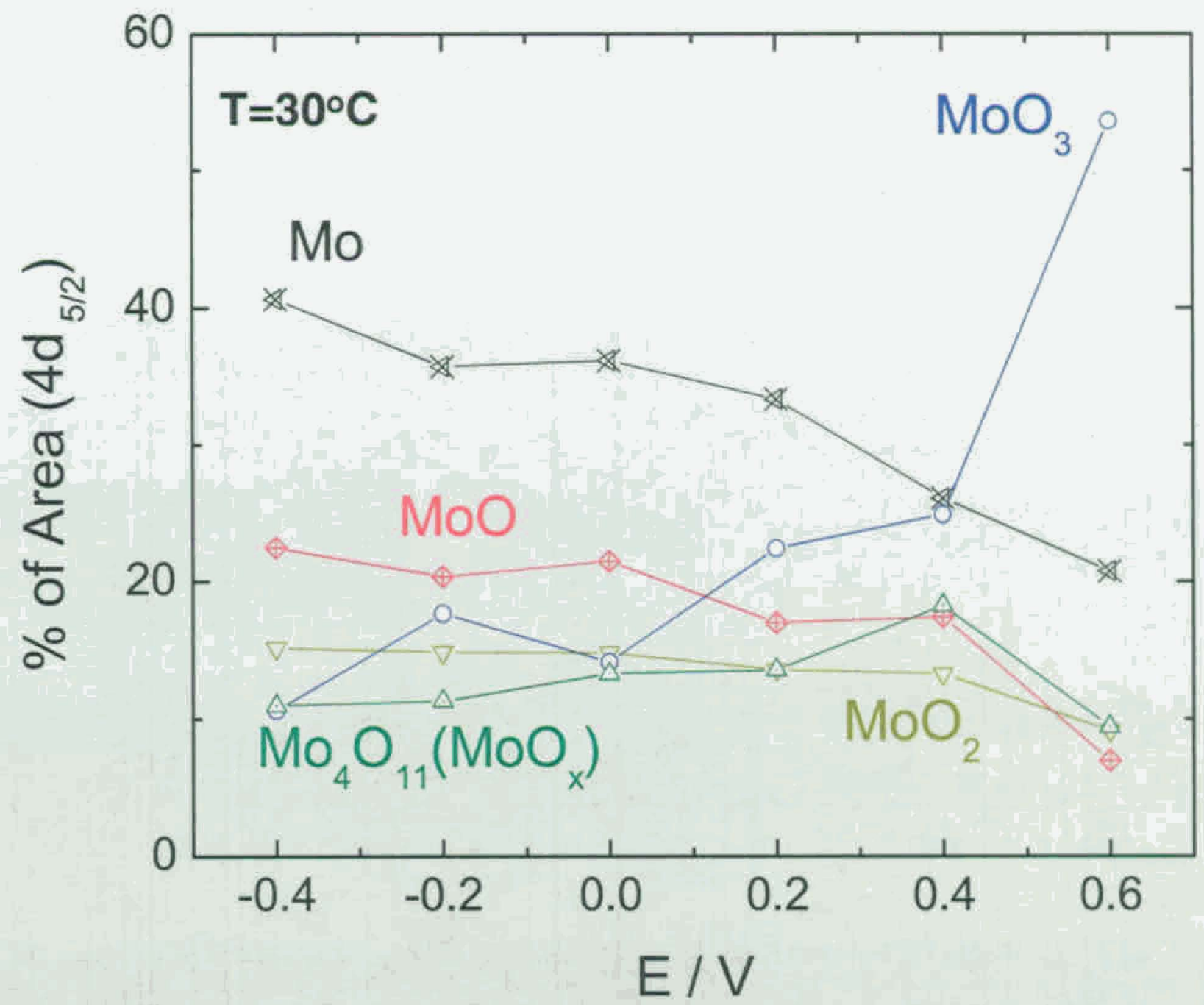




\section{Kinetics of cathodic reduction...}

\section{Surface Analysis. W High Resolution XPS.}

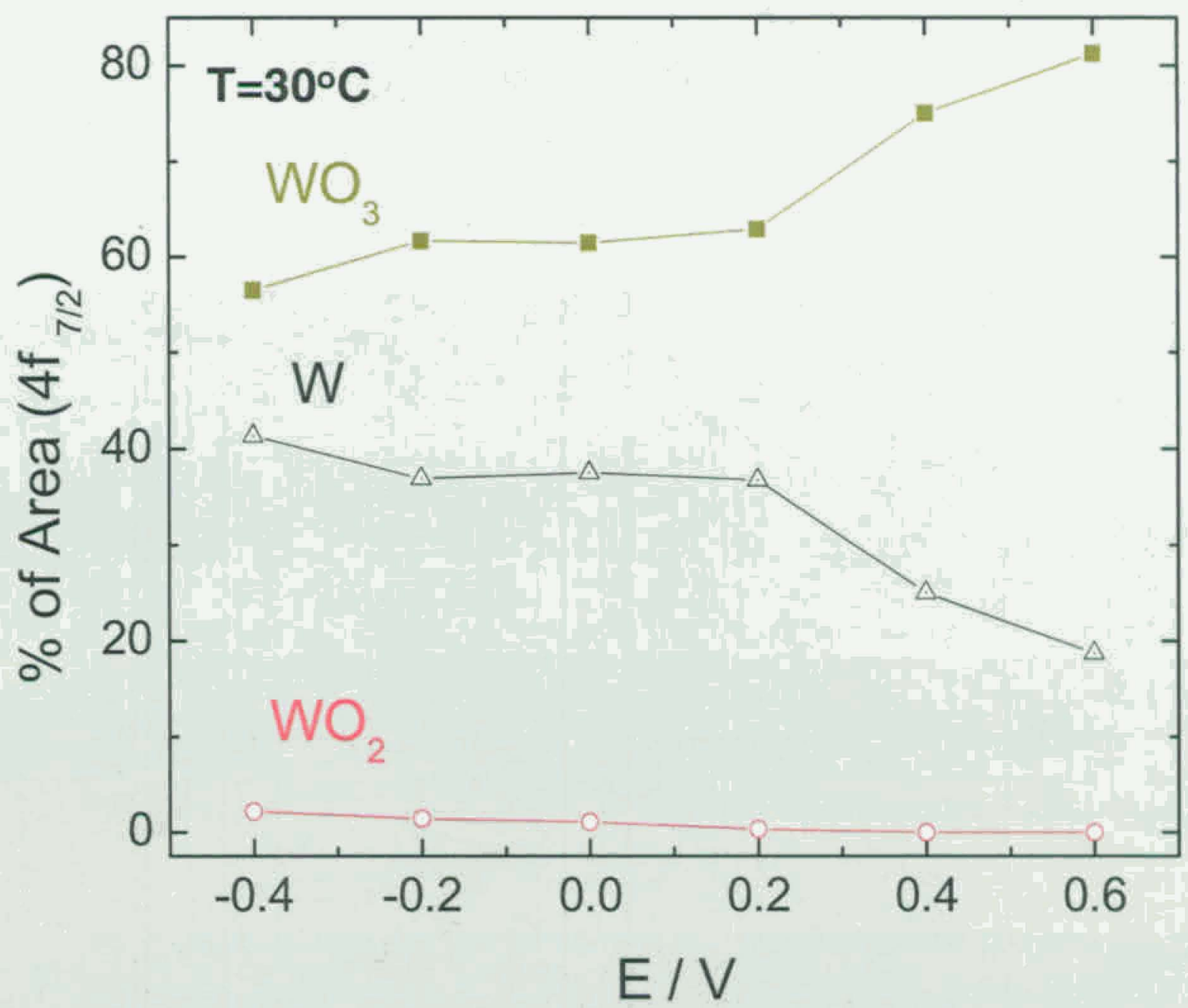




\section{Kinetics of cathodic reduction...}

\section{Surface Analysis. High Resolution XPS Results.}
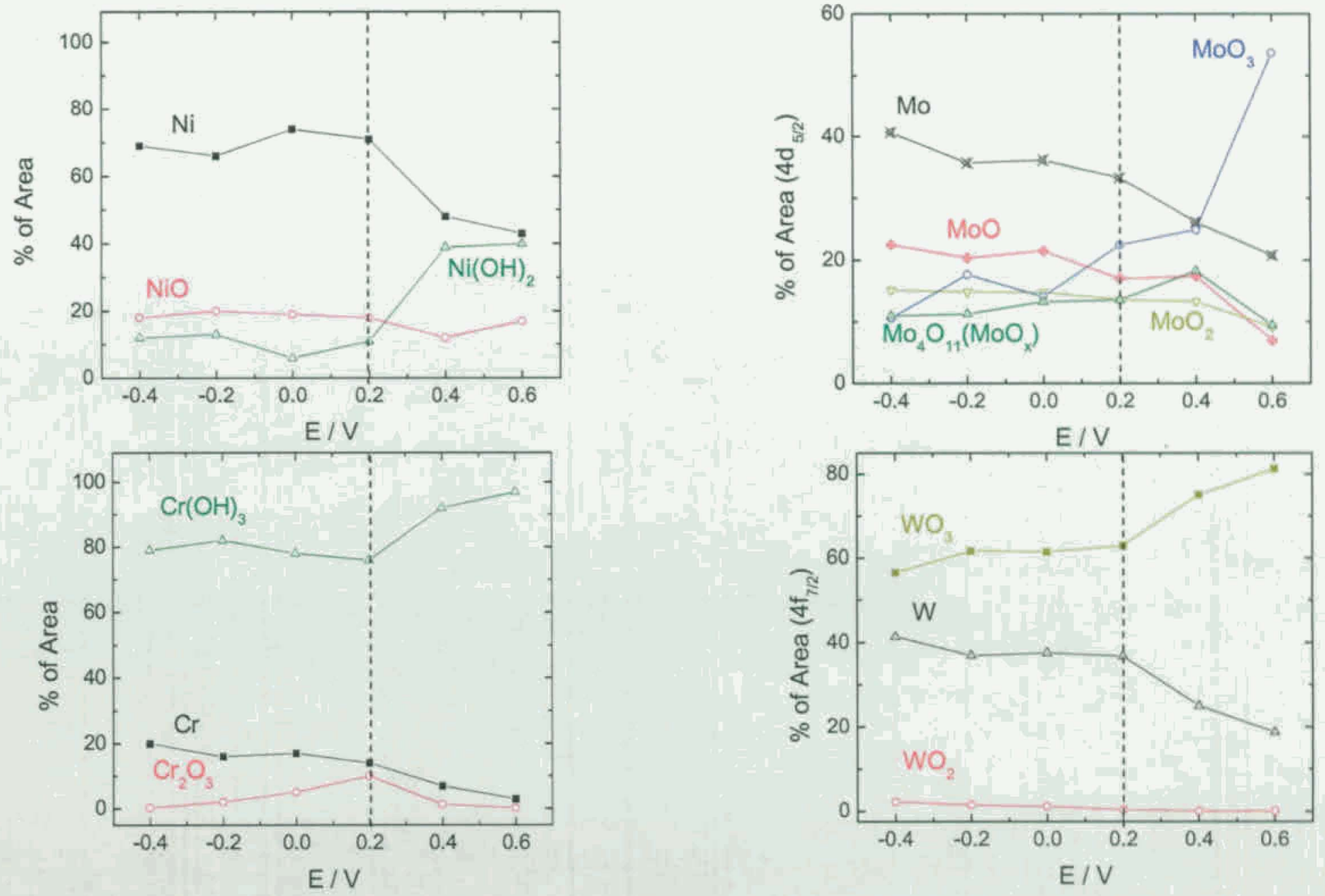


\section{Kinetics of cathodic reduction... EIS experimental conditions.}

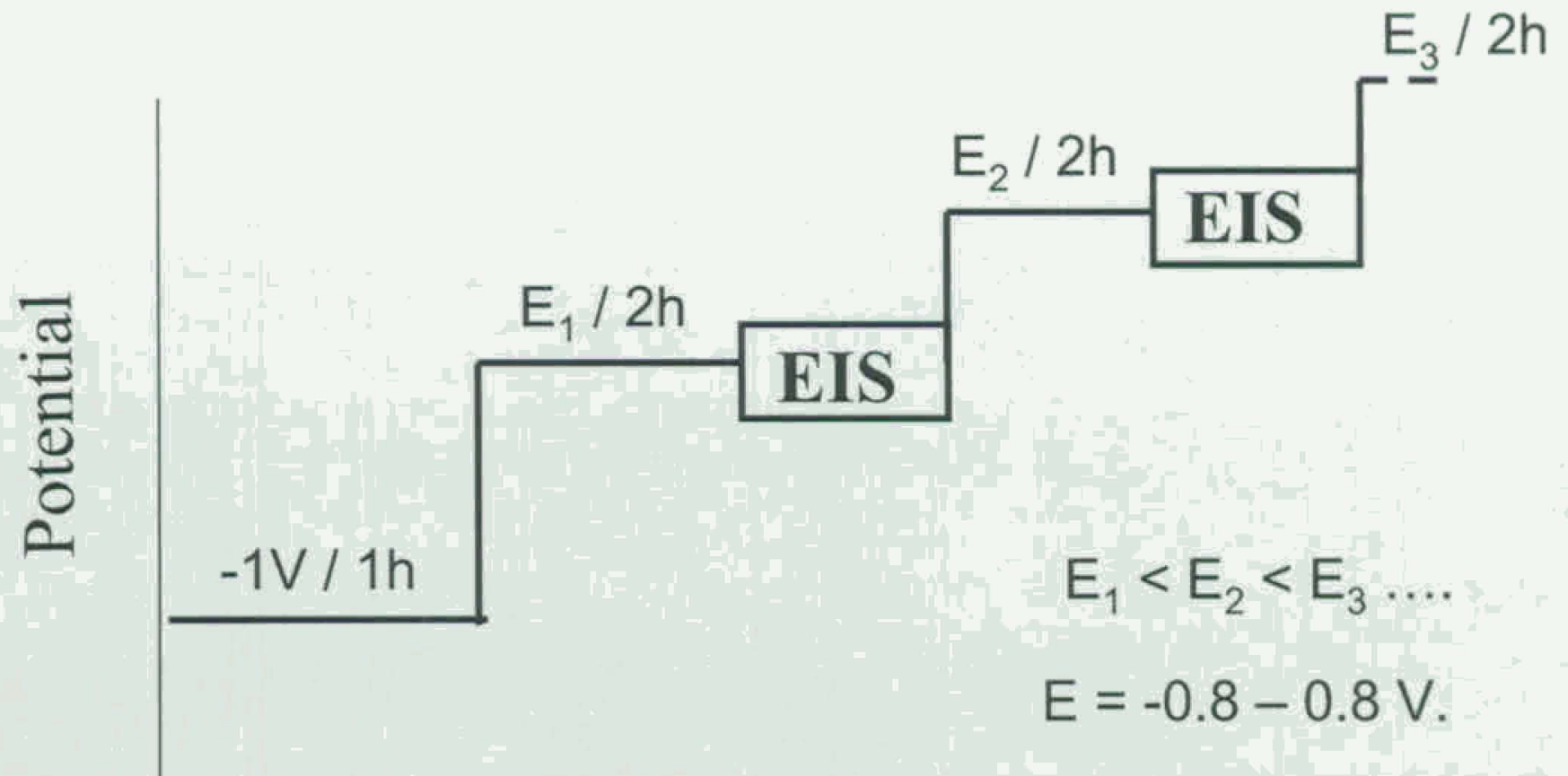

Time 


\section{Kinetics of cathodic reduction...}

\section{Surface Analysis Model.}

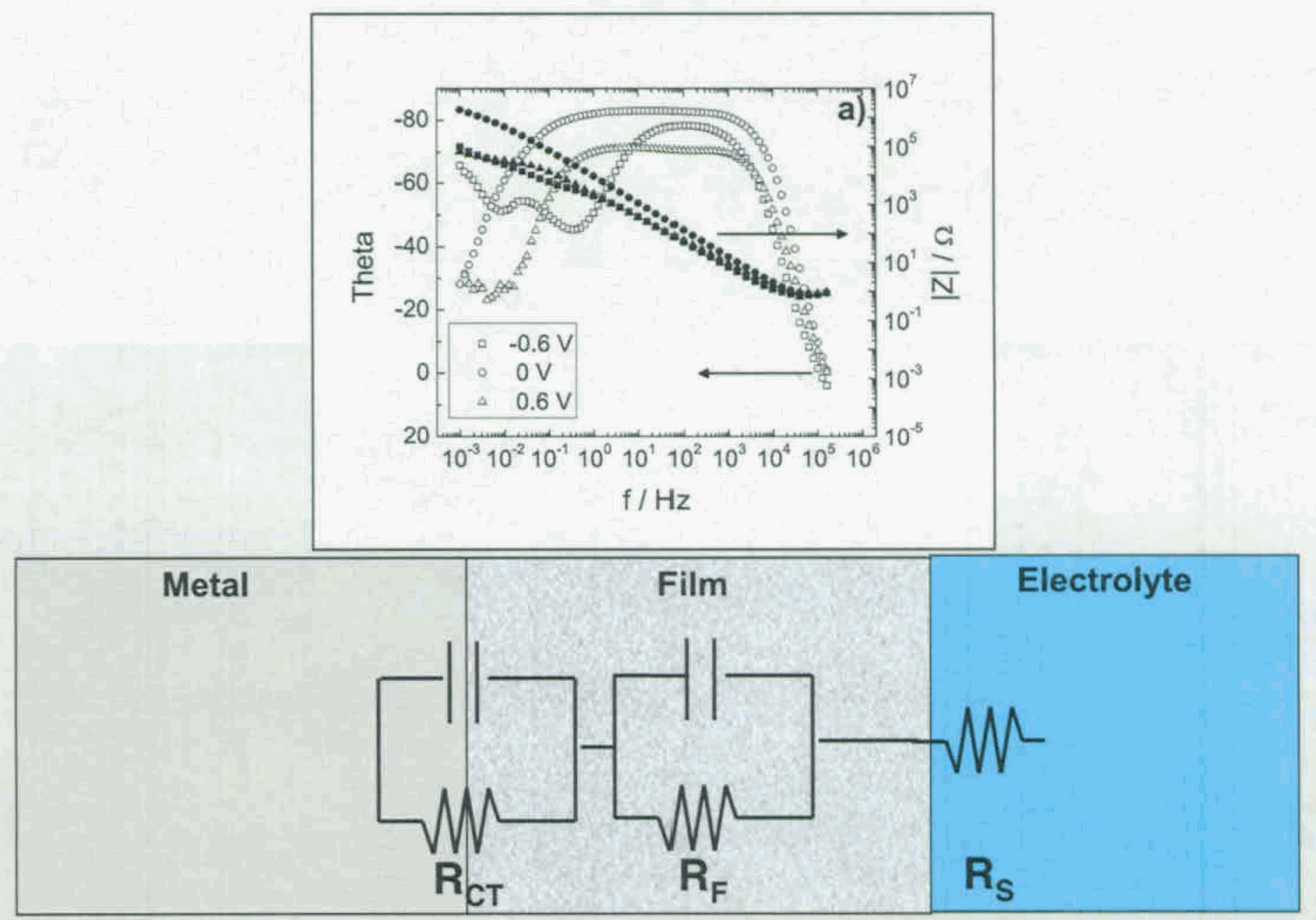

$$
\mathbf{R}_{\mathrm{P}}=\mathbf{R}_{\mathrm{CT}}+\mathbf{R}_{\mathrm{F}}+\mathbf{R}_{\mathrm{S}} \text { at } \omega=0
$$




\section{Kinetics of cathodic reduction...}

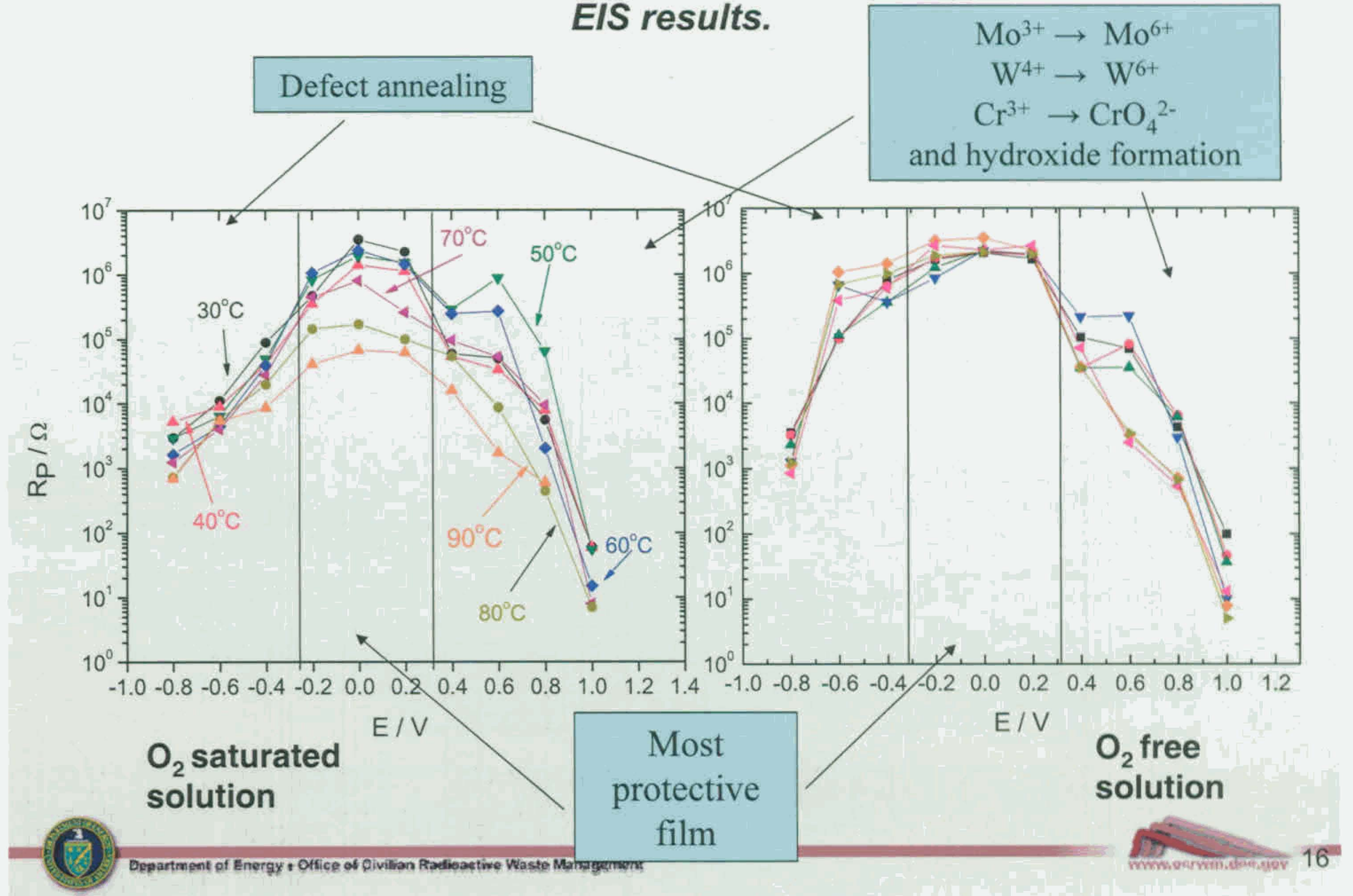




\section{Kinetics of cathodic reduction...}

\section{EIS. Temperature dependence.}
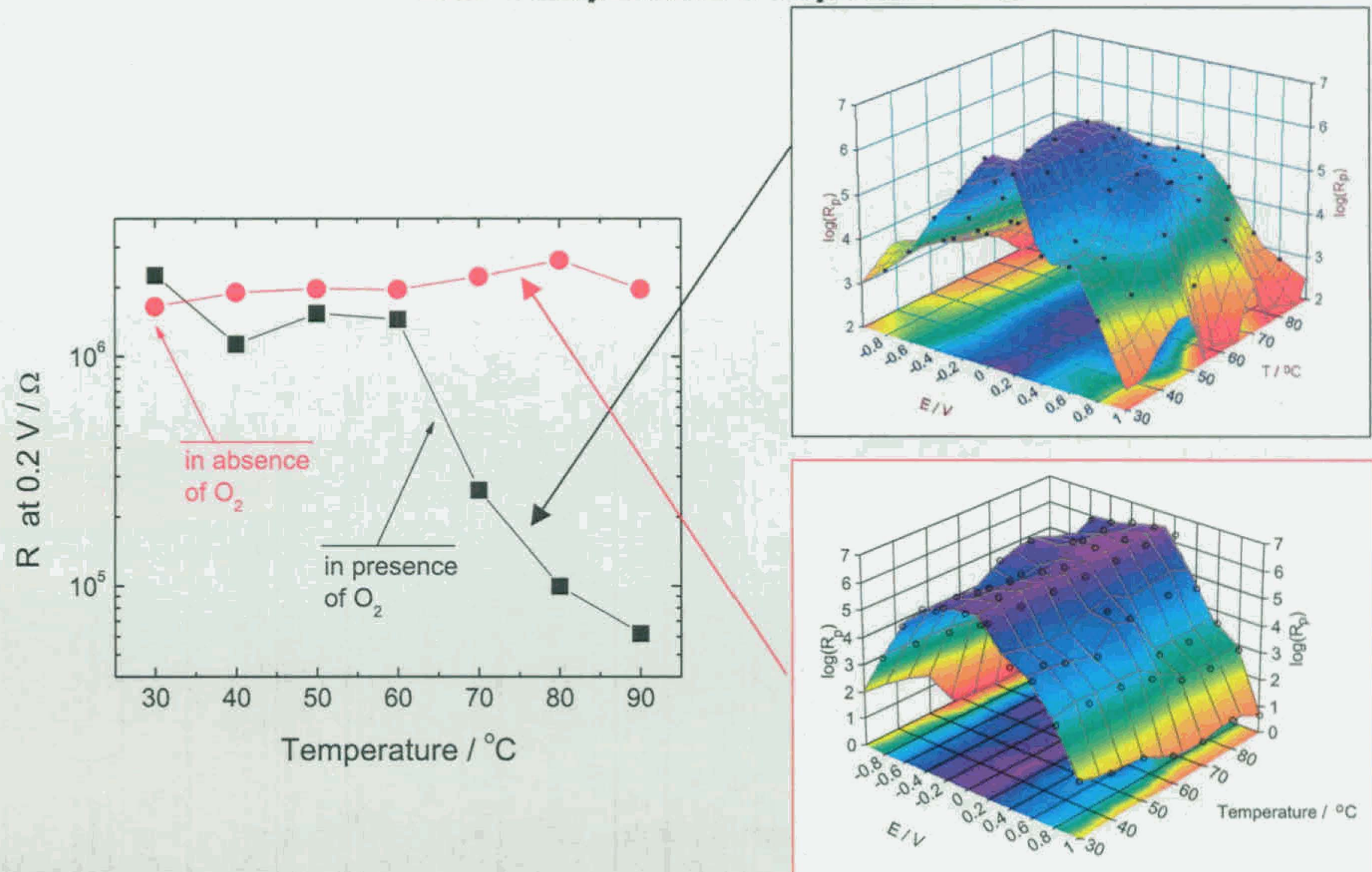


\section{Kinetics of cathodic reduction... \\ Oxygen reduction experimental conditions.}

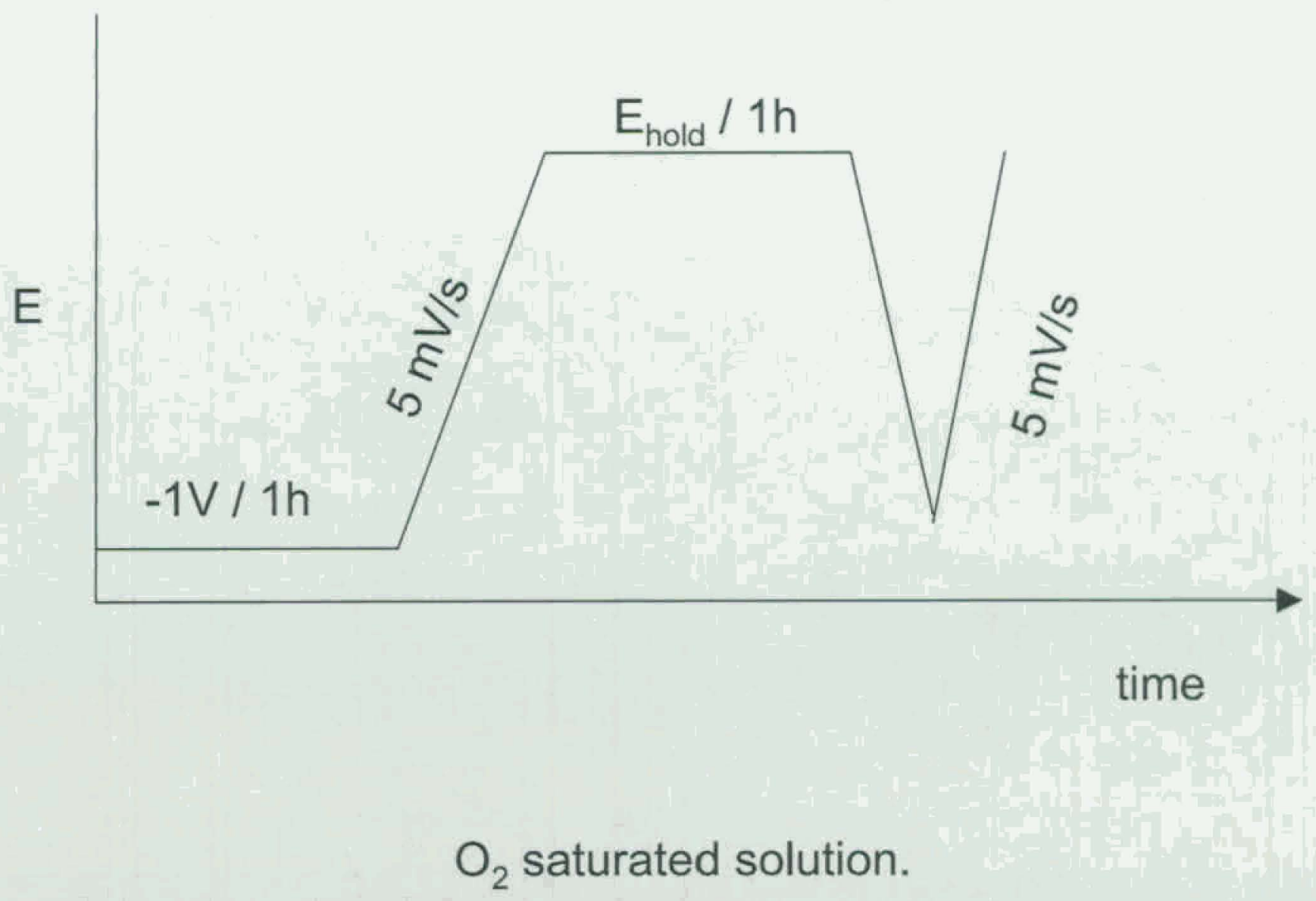




\section{Kinetics of cathodic reduction... Oxygen reduction.}

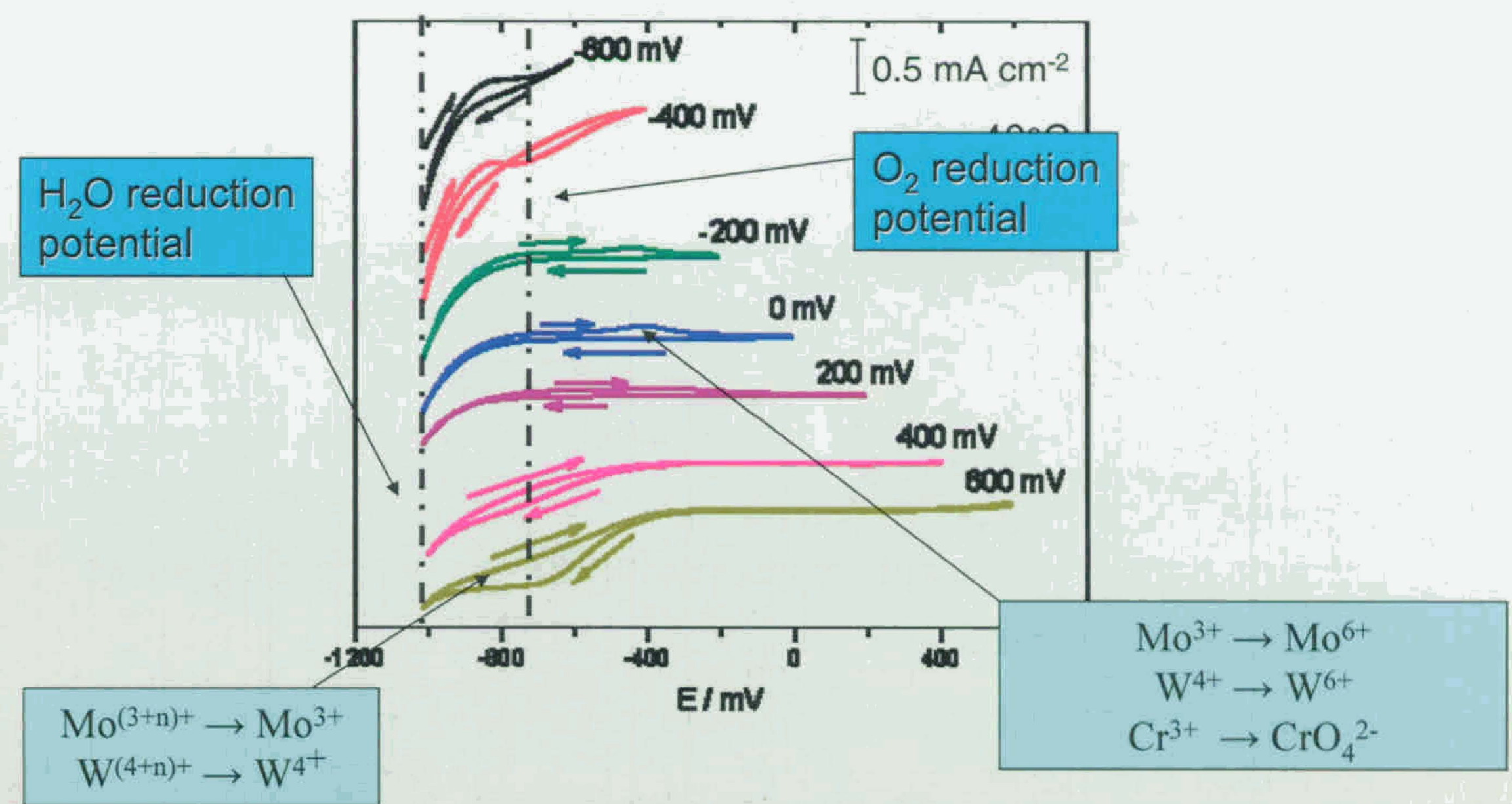




\section{Kinetics of cathodic reduction... Oxygen reduction.}
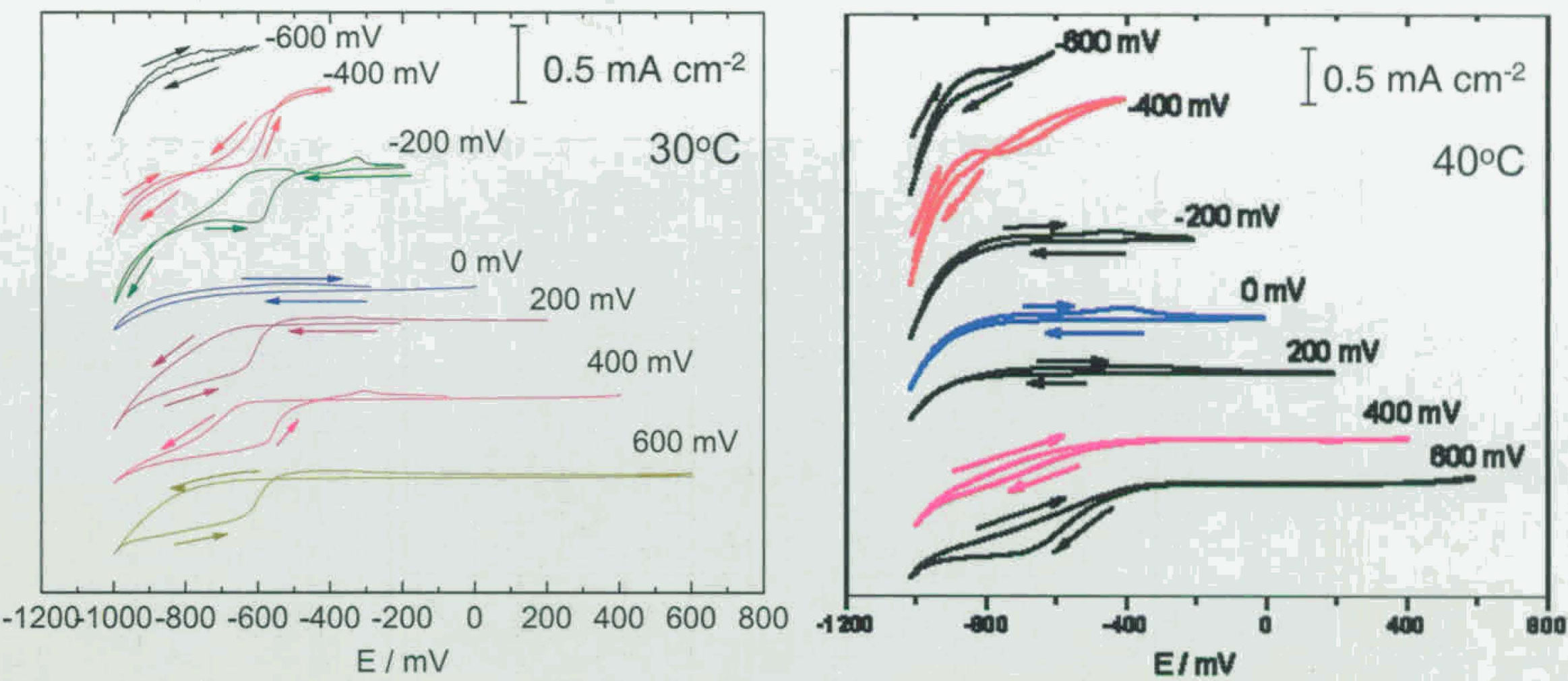


\section{Kinetics of cathodic reduction... Oxygen reduction.}
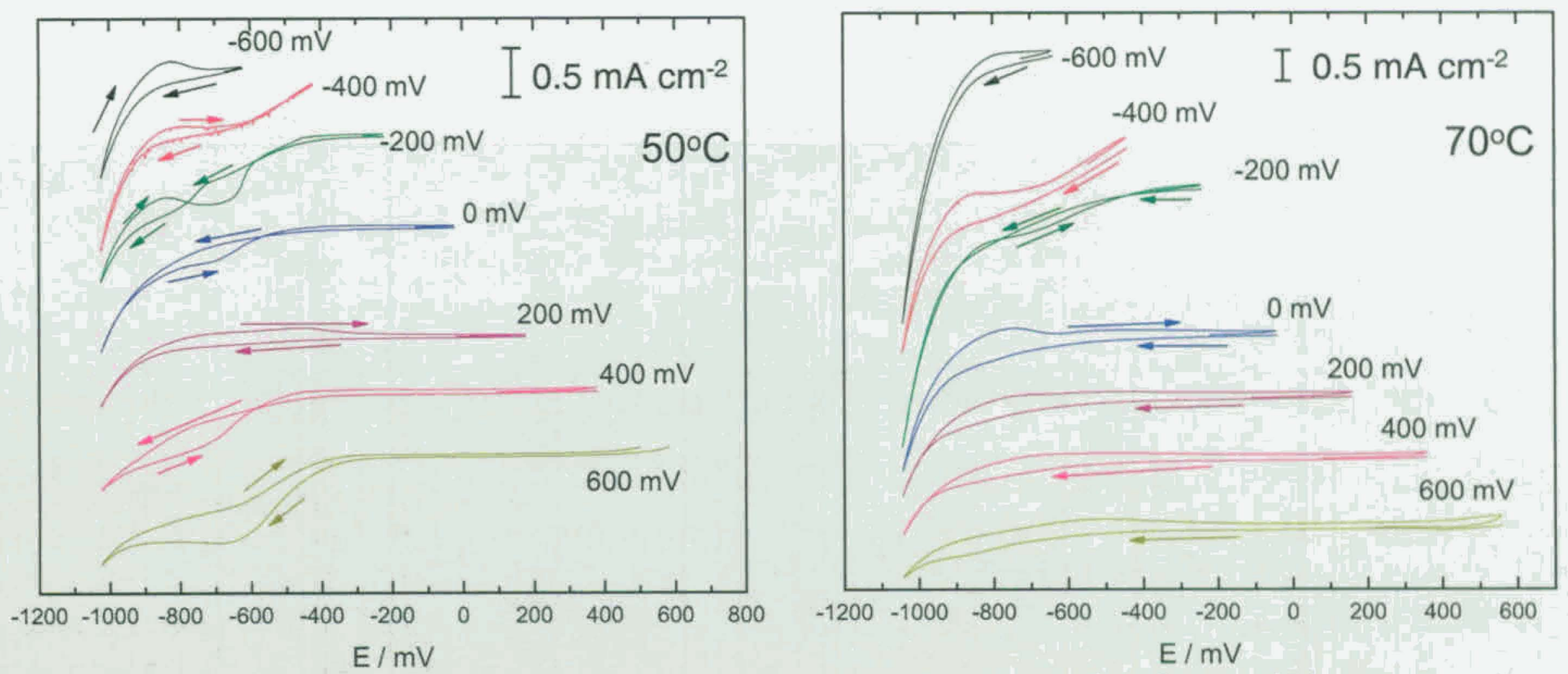


\section{Kinetics of cathodic reduction... \\ Summary.}

- Electrical and compositional properties of the protective film determined by EIS and XPS

- Film polarization resistance depends on pre-oxidation potential with a maximum in the potential interval -0.3 to $0.3 \mathrm{~V}$

- Cyclic voltammograms demonstrate that Alloy 22 can support oxygen reduction reaction under some conditions

- XPS data show that the composition, and perhaps also the thickness, of the oxide film on Alloy 22 have a significant effect on the alloys ability to suppress oxygen reduction

- The role of Mo in determining the corrosion resistance of Ni-Cr-Mo-W alloys should be elucidated closely taking into account the role of $\mathrm{Mo}$ as a supercapacitor and catalyst for $\mathrm{O}_{2}$ electroreduction 


\section{Co-workers.}

Prof. David Shoesmith

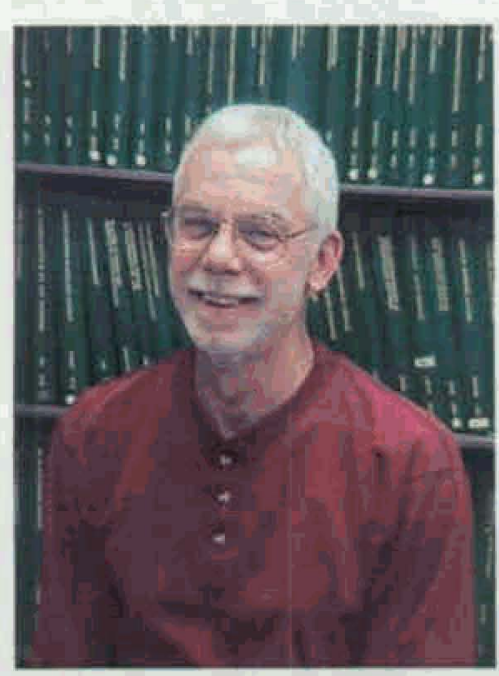

Grad. Student Brend Sherar

Grad. Student Pellumb Jakupi
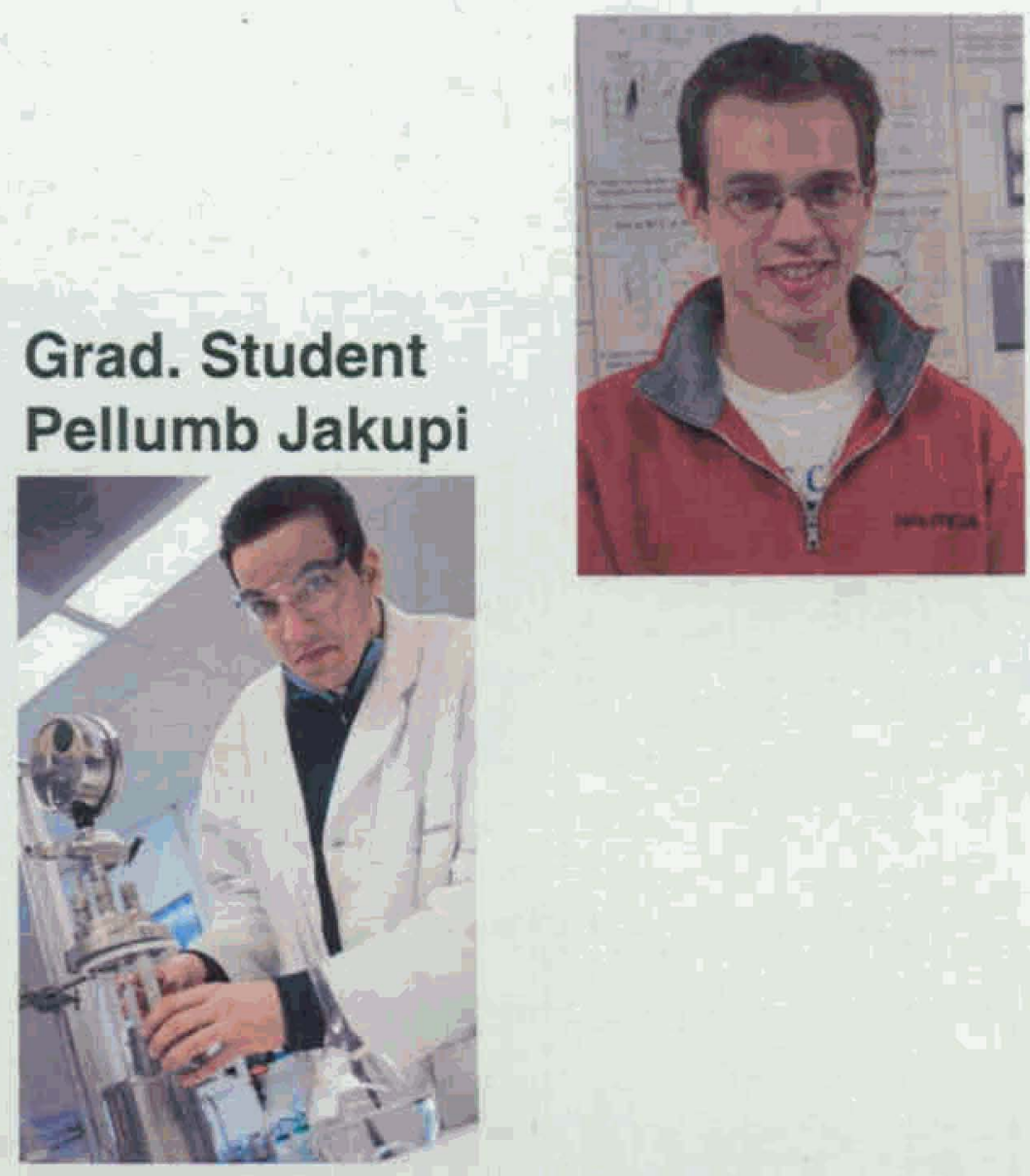

\section{Dr. Jamie Noël}

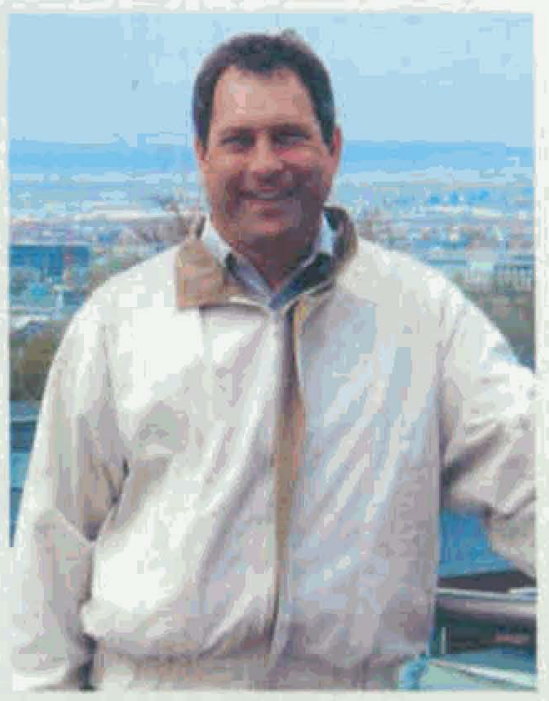




\section{Shoesmith's Group}

http://publish.uwo.ca/ ecsweb/

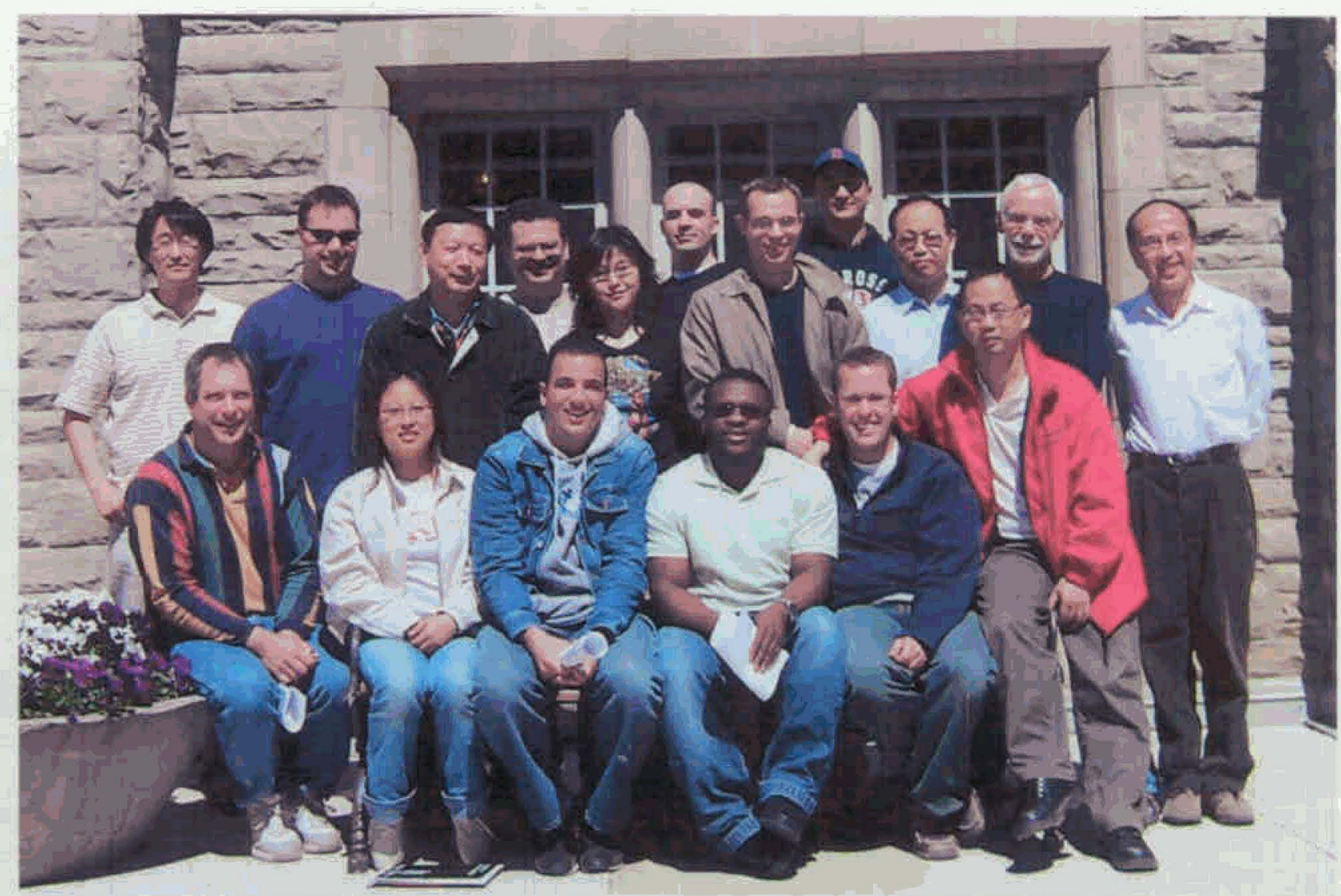

